\title{
Changes in lung aeration and cross-sectional areas of the pulmonary vascular tree in animals exposed to oxygen up to $0.3 \mathrm{MPa}$
}

\author{
Piotr Siermontowski ${ }_{\text {ABCD }}$, Maciej Konarski ${ }_{\text {BCDEF, }}^{1}$ Agnieszka Pedrycz ${ }_{\text {CDEF }}$, Katarzyna Pleskacz ${ }_{\text {BCEFG' }}^{1}$ \\ Dorota Kaczerska ${ }_{\text {ACDEFG }}$
}

${ }^{1}$ Department of Maritime \& Hyperbaric, Medicine Military Institute of Medicine, 81-103 Gdynia

${ }^{2}$ Department of Histology and Embryology with Laboratory of Experimental Cytology, Medical University of Lublin, 20-080 Lublin, Poland

${ }^{3}$ Department of Clinical Nutrition, Medical University of Gdańsk, 80-210 Gdańsk, Poland

\begin{abstract}
Clinical observations and results of experimental studies have demonstrated airway oxygen toxicity both in normo- and in hyperbarism. The majority of studies regard the lung parenchymal changes and only single ones focus on the effects of oxygen hyperbarism on the airway. The aim of the present study was to assess the effects of oxygen hyperbarism and the time of its use on morphological changes in the tracheal mucous and fibrous membrane.

An increasing partial pressure of oxygen causes an increase in the area of pulmonary interstitial structures and an initial decrease in the diameter of septal vessels followed by their dilation. Together with an increase in exposure times and values of hyperpressure, alveolar lumen oedema increases. In general, decreases in the pulmonary alveolar lumen areas predominate.

An increase in oxygen hyperbarism caused thickening of the tracheal mucous and fibrous membrane and simultaneous constriction of tracheal lumen. The changes enhanced together with increasing times of oxygen hyperbarism. The most common change observed was interstitial oedema with dilation of the vascular bed. Similar tendencies maintained with an increasing time of hyperbarism.
\end{abstract}

Key words: oxygen, hyperbarism, morphometry, lungs, trachea

\section{Introduction}

In recent decades, an increasing interest in the issues of oxygen toxicity was observed, mainly associated with possible effects of oxygen on the ageing processes. However, some of the studies were also related to a wider use of this gas in diving works, hyperbaric and atmospheric pressure therapy $[1,2,3]$ as well as in long-term oxygen therapy of patients with respiratory failure.

The risk of $\mathrm{O} 2$ toxicity increases proportionally to increases in oxygen partial pressures in the inspired gas mixture and prolonged exposure times. At high enough pressure and exposure time, oxygen can cause incremental functional impairment, including severe chemical damage to or even destruction of each living cell [4].

Although the specific reactions have not been fully elucidated, it is commonly accepted that toxic effects of oxygen develop in the mechanism of generation of its reactive species [5] and interactions with the adjacent cell structures, which leads to functional and morphological deficits [5, 6,7,8,9], in which nitric oxide (NO) and its derivatives are involved [10, 11].

When a healthy man or animal is exposed to oxygen at toxic partial pressure, the sequence and severity of symptoms observed in various organs and tissues depend on their relative susceptibility to hyperbaric oxygen and $\mathrm{O} 2$ dose [4]. The oxygen dose for a particular tissue is determined by the balance of such factors as arterial partial pressure of oxygen, extent of blood flow, metabolic activity of the tissue and density of capillary circulation. Since the above factors are not uniform for the entire body, particular organs and tissues are exposed to $\mathrm{O} 2$ in the extreme wide ranges of concentrations during respiration $[4,12,13]$.

When oxygen partial pressure in pulmonary alveoli exceeds arterial paO2, the lungs are exposed to too high oxygen pressures, higher than any other organ. At oxygen pressure of 0.05 to $0.2 \mathrm{MPa}$, maximum times of exposure are limited by the development of pulmonary oxygen toxicity symptoms $[4,13,14,15]$. 
Beside the clinical symptoms such as dyspnoea, pharyngeal and/or thoracic pain and burning, cough, retrosternal pain, easy fatigue $[14,16,17]$, the basic measurable clinical parameter of pulmonary oxygen toxicity is decreased vital capacity $[3,17]$.

The available studies provide detailed information on the mechanisms and consequences of oxygen toxicity at the level of pulmonary parenchymal constituents, i.e. pulmonary alveoli, alveolar ducts and fine bronchi $[11,17,18]$, yet the studies regarding the pathology of large bronchi and trachea are difficult to be found. As far as pulmonary oxygen toxicity is concerned, researchers focus on its measurable consequences in relation to the lower level of the respiratory tract, i.e. decreased vital capacity, reduced specific properties of lung elasticity, impaired flow in fine bronchi and bronchioles, as well as measurable sequels of impaired gas exchange at the level of pulmonary alveoli.

The literature data concerning the pathology of large bronchi and trachea are sparse (particularly morphometric ones). It is generally accepted that increasing oxygen toxicity induces disorders in the airway flow and increased airway resistance accompanying this phenomenon do not depend on the pathology affecting the larger bronchi and trachea [13, 19].

Considering the above, our team decided to undertake the study in an experimental animal model.

Aim:

The aim of the present study was to compare the morphometrically-examined changes in lung aeration and tracheal changes in experimental animals exposed to oxygen hyperbarism at up to 0.3 MPa.

\section{Material and methods:}

The study was performed in a 30-litre high-pressure chamber designed for small animals, which enabled to generate the pressure up to $100 \mathrm{mH} 2 \mathrm{O}$.

The Black Hood rats of both sexes were divided into two groups: experimental and control. Prior to the experiment, all rats were kept in cages, 6 animals each. Before hyperbaric exposure, animals were accustomed to the chamber environment by placing them inside the chamber for 30 to 120 minutes, 5 days in a row. Moreover, animals were accustomed to noise generated during forcing the gas mixture into the chamber to minimise possible artefact morphological changes associated with stress. The control rats (6 animals) were not subjected to any procedures and were only accustomed to staying in the pressure chamber. Another 6 procedure-control animals were kept in the chamber for 60 minutes under the pure oxygen environment at the atmospheric pressure.

The experimental animals were divided into subgroups, 6 animals each and subjected to hyperbaric exposure at the pressures of 5,10 , and 20 $\mathrm{mH} 2 \mathrm{O}$, respectively. In the individual subgroups, four different exposure times were used: 30, 60, 120 and 240 minutes. The division of animals is presented in table 1.

Table 1. Division of study animals

\begin{tabular}{|c|c|c|}
\hline Group & Exposure time & $\begin{array}{c}\text { Number } \\
\text { of ani- } \\
\text { mals }\end{array}$ \\
\hline Air control & 0 & 6 \\
\hline $\begin{array}{c}\text { Procedure } \\
\text { control } \\
\text { o.1 MPa } \\
\text { oxygen }\end{array}$ & 60 & 6 \\
\hline \multirow{2}{*}{$\begin{array}{c}\text { o.15 MPa } \\
\text { oxygen }\end{array}$} & & \\
\cline { 2 - 3 } & 30 & 6 \\
\cline { 2 - 3 } & 60 & 6 \\
\hline \multirow{2}{*}{$\begin{array}{c}\text { oxygen } \\
\text { oxy }\end{array}$} & 120 & 6 \\
\cline { 2 - 3 } & 240 & 6 \\
\cline { 2 - 3 } & 30 & 6 \\
\cline { 2 - 3 } & 120 & 6 \\
\hline \multirow{2}{*}{\begin{tabular}{c} 
oxygen \\
\cline { 2 - 3 }
\end{tabular}} & 240 & 6 \\
\cline { 2 - 3 } & 30 & 6 \\
\cline { 2 - 3 } & 60 & 6 \\
\hline
\end{tabular}

Three rats were placed in the chamber. After closing the hatch, the chamber was rinsed with oxygen to remove air. Subsequently, the pressure in the chamber was increased with the speed of $0.1 \mathrm{MPa}$ until the pressure planned for a given exposure time was achieved. Once achieved, the exposure time countdown was initiated.

Continuous decompression was performed with the speed of $0.05 \mathrm{MPa}$ per minute until atmospheric pressure was achieved. Subsequently, the chamber was opened and animals were taken out.

Immediately after the experiment, the rats were killed by disruption the spinal cord continuity and subjected to pathomorphological macroscopic examinations. After incising the neck integuments, the trachea was prepared and ligated in two places to prevent lung collapse. Subsequently, the entire package of thoracic organs was taken out. Organ packages were fixed in 10\% neutralized formalin in the $200 \mathrm{ml}$ marked containers at $4 \mathrm{oC}$. Micro- 
scopic specimens were prepared using the paraffin method. The paraffin blocks obtained from each animal contained:

- cross-sections of the entire lungs, left and right lung

- cross-sections of the trachea collected below the ligatures and directly above the bifurcation into main bronchi.

During the first stage of macroscopic and microscopic examinations, each experimental group was divided into two subgroups, according to sex. However, the initial analysis of results demonstrated that the results were not sex-dependent; therefore, both sexes were considered as one group.

The 5-micrometre tissue sections were prepared using a microtone and stained with haematoxylin-eosin.

The specimens were examined qualitatively under an Olympus BHSU light microscope using the magnification ranges from 50 to $400 x$.

A 121-point Haug`s grid was used for microstereological examinations; calculations were performed with the use of 20x magnification. During the examinations of lungs, hits of grid line intersections into the alveolar lumen (ALV) and other pulmonary structures were summed up.

In the tracheal examinations, the number of hits of grid line crossing into the tracheal lumen, mucosa and the remaining components of the tracheal wall (fibrosus membrane together with bronchial cartilages) were summed up. In the case of tracheal measurements, it was not possible to place the entire grid over anatomical structures, thus the summary number of hits was different in each measurement.

Based on the results, the following coefficients were calculated:

- of the ratio of the tracheal lumen area - mucosal area ratio

-of the tracheal lumen area - fibrous membrane area ratio

- of the entire tracheal wall cross-sectional area - lumen area ratio.

Results were statistically analysed using the Shapiro-Wilk and Lilliefors tests to assess the normality of distribution (the majority of variables were not normally distributed) as well as the Kruskal-Wallis test (ANOVA).

\section{Results}

The microscopic examinations demonstrated atelectasis increasing with prolongation of exposure time and increased oxygen partial pressures. A decrease in the area occupied by pulmonary alveoli in the specimen was accompanied by an increased amount of low protein fluid in the alveolar lumen, corresponding to pulmonary oedema as well as an increase in the surface occupied by the pulmonary stroma. Thickened intraalveolar septa were particularly visible, which corresponded to interstitial oedema.

The mean values calculated for the results obtained and their descriptive statistics are presented in table 2 .

Table 2. Descriptive statistics for measurement results

\begin{tabular}{|l|l|l|l|l|l|l|}
\hline $\begin{array}{l}\text { Pressure } \\
{[\mathrm{MPa}]}\end{array}$ & $\begin{array}{l}\text { Expo- } \\
\text { sure } \\
\text { time } \\
{[\mathrm{min}]}\end{array}$ & $\begin{array}{l}\text { ALV } \\
\text { mean }\end{array}$ & $\begin{array}{l}\text { ALV } \\
\text { standard } \\
\text { deviation }\end{array}$ & $\begin{array}{l}\text { ALV } \\
\text { Q25 }\end{array}$ & $\begin{array}{l}\text { ALV } \\
\text { Q75 }\end{array}$ & $\begin{array}{l}\text { ALV } \\
\text { me- } \\
\text { dian }\end{array}$ \\
\hline control & control & 86.5 & 1.64992 & 85 & 87 & 86.5 \\
\hline 0.1 & 1 & 76.86 & 9.16072 & 70 & 84 & 79.5 \\
\hline \multirow{3}{*}{0.15} & 1 & 81.72 & 7.48173 & 77 & 88 & 83.5 \\
\cline { 2 - 8 } & 2 & 82.95 & 6.69006 & 78 & 88 & 84 \\
\cline { 2 - 8 } & 240 & 86.97778 & 3.50642 & 84 & 89 & 87 \\
\hline \multirow{3}{*}{0.2} & 60 & 78.95714 & 6.28187 & 74 & 83 & 80 \\
\cline { 2 - 7 } & 120 & 79.21667 & 6.67932 & 75 & 85 & 78.5 \\
\cline { 2 - 7 } & 240 & 72.1 & 8.113972 & 67 & 78 & 73 \\
\hline \multirow{3}{*}{0.3} & 60 & 72.66667 & 6.53197 & 68 & 77 & 73 \\
\cline { 2 - 7 } & 120 & 66.42222 & 7.30345 & 62 & 71 & 69 \\
\cline { 2 - 7 } & 240 & 70.50909 & 4.59417 & 68 & 74 & 70 \\
\hline
\end{tabular}

The animals died in the experimental groups exposed to $0.3 \mathrm{MPa}$ pressures. Therefore, it was assumed that when the death in the chamber did not occur earlier than after $80 \%$ of exposure time, the animal was treated as the remaining ones put to death after completion of hyperbaric exposure.

The changes in the number of hits into the pulmonary alveolar lumen for one-hour exposures at balanced pressures of $0.1 ; 0.15 ; 0.2 ; 0.3 \mathrm{MPa}$ are presented in Fig.1. 
Fig. 1. Results for individual hyperbaric pressures at 60-minute exposures (pressures expressed in metres of water column)

( $\mathrm{x}$-axis - hyperbaric pressure in $\mathrm{mH}_{2} \mathrm{O}, \mathrm{y}$ - number of hits into alveolar lumen $\square-$ mean $\square-$ mean \pm SD. $T$ $\perp$ mean $\pm \mathrm{SD}$ )

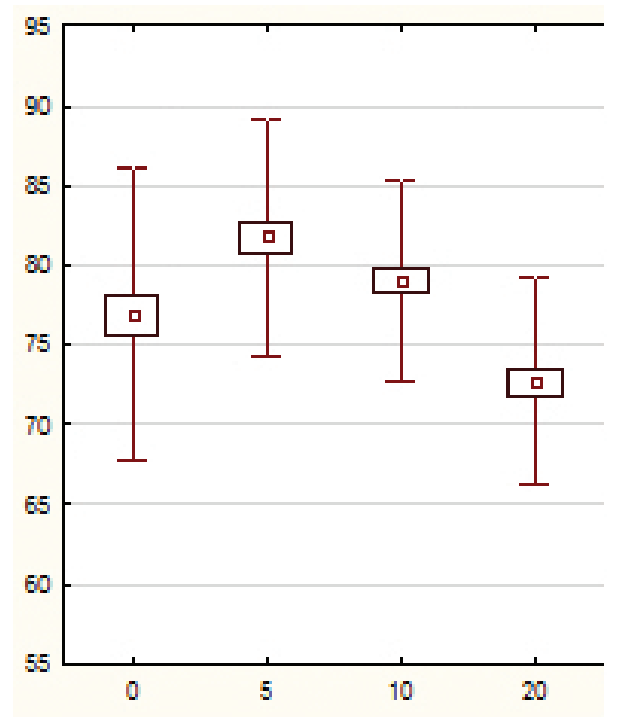

The changes in the number of hits into the pulmonary alveolar lumen for two-hour exposures at balanced pressures of $0.1,0.15,0.2$, and $0.3 \mathrm{MPa}$ are listed in Fig.2.

Fig. 2. Results for individual hyperbaric pressures at 120-minute exposure (pressures expresses in metres of water column)

( $\mathrm{x}$-axis - hyperbaric pressure in $\mathrm{mH} 2 \mathrm{O}, \mathrm{y}$ - number of hits into the alveolar lumen $\square-$ mean $\square-$ mean \pm SD. $\top^{\perp}$ mean $\pm \mathrm{SD}$ )

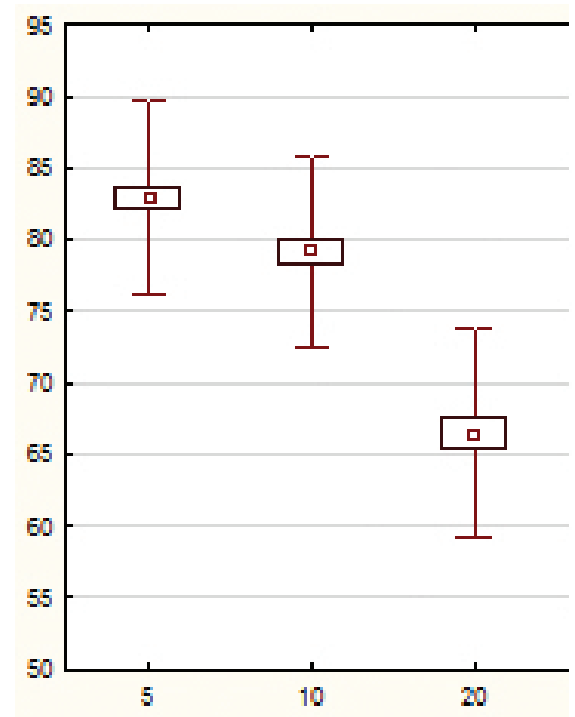

The changes in the number of hits into the alveolar lumen for 4-hour exposures at balanced pressures of $0.1,0.15,0.2,0.3 \mathrm{MPa}$ are presented in Fig. 3.
Fig. 3. Results for individual hyperbaric pressures at the 240-minute exposure (pressure expressed in metres of water column)

(x-axis - hyperbaric pressure in $\mathrm{mH} 2 \mathrm{O}, \mathrm{y}$ - number of hits into the alveolar lumen $\square-$ mean $\square-$ mean \pm SD. $\mathrm{T}^{\perp}$ mean $\pm \mathrm{SD}$ )

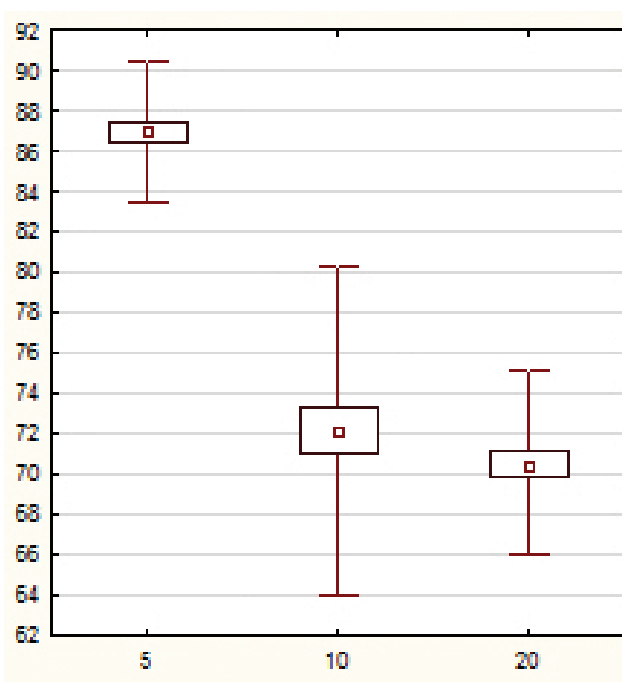

The ratio of cross-sectional area of the tracheal lumen to the cross-sectional area of the mucosa changed to the detriment of the tracheal lumen at the pressures higher than the $0.15 \mathrm{MPa}$ balanced ones. In the group exposed to balanced pressure of $0.15 \mathrm{MPa}$, an initial increase in the ratio of the cross-sectional area in favour of the tracheal lumen area, followed by a drop since the second hour of exposure. The findings are shown in Fig.4. The differences in values were statistically significant, except for the experimental group exposed to balanced pressure of $0.2 \mathrm{MPa}$ and exposure times of 2 and 4 hours.

Fig. 4. Changes in the ratio of tracheal lumen area to crosssectional mucosal area ( pressure expressed in metres of water column)

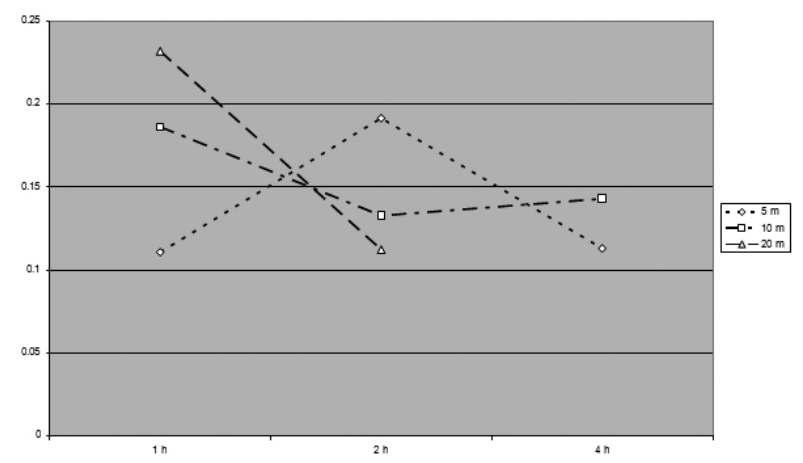


The changes in the ratio of tracheal lumen-fibrous membrane areas were comparable to those of the mucosa. The differences were statistically significant, except for the mucosa.

The directions of changes observed in individual layers of the tracheal wall confirmed „reverse" comparison of the ratio of the lumen area to cross-sectional area of the entire tracheal wall. Moreover, varied reactions depending on the $\mathrm{O} 2$ pressure and exposure time were found. The results are depicted in fig. 5.

Fig. 5. Changes in the ratio of lumen area to cross-sectional area of the entire tracheal wall (pressures expressed in metres of water column)

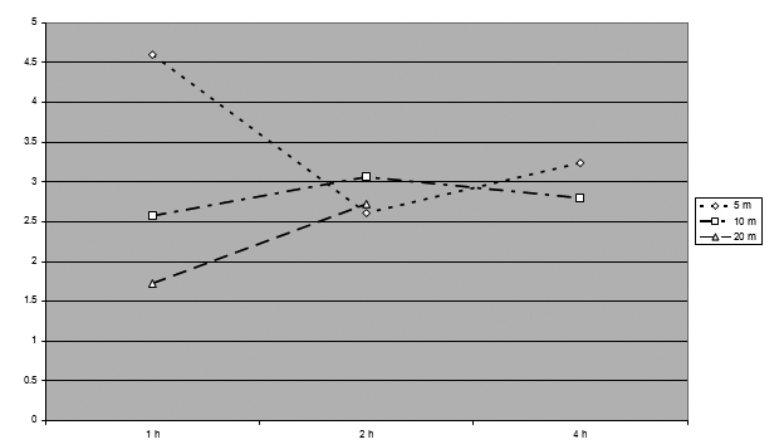

\section{Discussion}

The qualitative results of experiments coincide with expectations: in all study groups at a given exposure time, increased partial pressure of oxygen caused a decrease in pulmonary alveolar lumen area in microscopic specimens [20,21]. However, in none of the specimens, including those from animals who died during experiments, atelectasis combined with oedema led to lung airlessness, which would explain deaths of animals. Therefore, it was assumed that deaths was not caused by oxygen toxicity of the lung (in consequence respiratory failure) but by other disorders, e.g. cerebral oxygen poisoning, which is particularly likely due to the fact that deaths were observed only in groups in which oxygen partial pressure exceeded $0.3 \mathrm{MPa}$ [2].

Moreover, qualitative examinations demonstrated a decrease in the area occupied by the pulmonary alveolar lumen in relation to other parenchymal structures and oedema fluid $[1,4,20,21]$. For the majority of measurements, the changes were statistically significant.
As far as divergent results are concerned, it was assumed that an increased mean for balanced pressure of $0.15 \mathrm{MPa}$ during the 60-minute exposure most likely resulted from the fact that in this experimental group the qualitative examinations showed intensified vasoconstriction, both of small vessels in the pulmonary alveolar walls and of medium vessels, which could have led to an increase in the cross-sectional area of pulmonary alveolar lumen at the expense of the lumen of blood vessels. Reduced lung aeration found during morphometric examinations was several times higher for each hyperbaric pressure value and each exposure time than the expected values calculated based on coefficients applied for humans. The differences, whose values exceeded those predicted by several to over 20 times indicate that rats, most commonly used to study the physiology and pathology of hyperbarism, are not most suitable for studies on pulmonary oxygen toxicity; moreover, the results, although consistent with the trend, cannot be directly applied to humans.

The findings enable to conclude that respiration with oxygen under elevated pressure significantly affects the changes in the cross-sectional area of the entire tracheal lumen and of the individual layers of its wall. The changes in each coefficient depend both on exposure time and oxygen pressure values.

The comparison of our results with the literature data reveals that the effects of increasing oxygen toxicity observed by other authors mainly at the level of bronchioles and pulmonary parenchyma, under suitably extreme conditions of exposure to hyperbaric oxygen (in our study at $\mathrm{pIO} 2=0.2$ and $0.3 \mathrm{MPa}$ and 2 or 4-hour exposure time) result in reduced effective airway lumen and mucosal oedema at the level of large bronchi and trachea; in the case of balanced hyperbaric pressure of 0.2 $\mathrm{MPa}$ - of fibrous membrane as well.

Considering the results of studies in humans mentioned earlier, which were usually carried out at reduced pIO2, and resulted in specific clinical symptoms in the majority of the patients studied, it is difficult not to believe that the morphometric changes observed by us in experimental animals directly derive from increasing oxygen toxicity. The relations (described by Demchenko et al.) [19] resulting from metabolic effects of NO seem essential, i.e. high $\mathrm{pO} 2$ accelerates the production of NO by endothelial synthasis of NO (eNOS) in the vascular endothelium and by neuronal synthasis of NO (nNOS) in nerve endings, resulting 
in „switching” of hyperbaric oxygen exposure-induced vasoconstriction towards widening of blood vascular lumen and resultant airway mucous membrane congestion. The above mechanisms as the repair mechanisms after oxygen ventilator therapy were also described by Curley et al. [15]

According to the newest concepts, adverse effects of normobaric and hyperbaric oxygen on the lungs and brain are the integral components of pathophysiological continuum, whose common element is NO and its interactions with other biochemically-active substances (ions, free radicals, etc.) of proven importance for the pathogenesis of oxygen toxicity. Therefore, it is not surprising that morphological parameters of acute oxygen poisoning were found in the airways of rats that died during exposures, although the initial cause of their death was undoubtedly cerebral oxygen toxicity.

In our opinion, the above is also confirmed by the results obtained at pIO2 $=0.15 \mathrm{MPa}$, i.e. the partial oxygen pressure at the level similar to the values used in the majority of human studies. At such pIO2 values, exposure time is the essential factor determining the development of oxygen poisoning symptoms; this kind of relation is clearly visible in our findings at hyperbaric exposures prolonged to 4 hours. After a transient increase in effective airway lumen at 2-hour exposure time, most likely caused by activation of typical antioxidative protective mechanisms, associated with increasing oxidative stress and resulting in reduced cross-sectional vascular lumen area (which is a well known phenomenon), a resultant decrease in the effective lumen of this airway level is observed due to "overcoming" the protective mechanisms, including NO-dependent dilation of the blood vessel lumen [12].

Although the qualitative histological changes in the tracheal wall developing at increasing exposure times,were not analysed in detail in our study, the results of microscopic assessment seem to be fully consistent with the findings of studies dealing with (micro) structural changes of the respiratory system in the course of pulmonary oxygen toxicity $[22,23,24,25]$.

Another issue to consider is the extent the results in humans can be referred to animal models and vice versa. Some literature data indicate that rats are not an ideal model to be used in studies regarding pulmonary oxygen toxicity (in particular, at long exposure times), especially for 1:1 application of animal results to human population, in particular [18].

\section{Conclusions:}

1. Increased partial pressure of oxygen and prolonged hyperbaric exposure times result in reduced lung aeration in experimental animals.

2. An increase in changes in animals is multiple times higher, compared to the predicted values based on assumptions of calculations used in human pathologies.

3. Reduced effective lumen of the middle airway level observed in the animal model is directly related time- and oxygen partial pressure-increasing morphological parameters of oxygen poisoning concerning the tracheal wall and large bronchi.

4. Results of experimental studies in rats regarding oxygen toxicity for the middle airway level, as well as pulmonary oxygen toxicity, should be referred to humans with great caution.

\section{References:}

1. Allen BW, Demchenko IT, Piantadosi CA. Two faces of nitric oxide: implications for cellular mechanisms of oxygen toxicity. J Appl Physiol 2009; 106: 662667 - doi: 10.1152/japplphysiol.91109.2008. Epub 2008 Oct 9

2. Caldwell PR, Lee WL, Schildkraut HS, Archibald ER. Changes in lung volume, diffusing capacity, and blood gases in men breathing oxygen. J Appl Physiol 1966; 21(5): 1477-1483.

3. Clark JM, Gelfand R, Flores ND, Lambertsen CJ, Pisarello JB. Pulmonary tolerance in man to continuous oxygen exposure at 3.0, 2.5, 2.0 and 1.5 ATA in Predictive Studies V. W: AA Bove, AJ Bachrach i LJ Greenbaum (Eds.) Proc Ninth International Symp Underwater and Hyperbaric Physiology. Undersea and Hyperbaric Medical Society, Bethesda 1987: 737-7495.

4. Clark JM, Jackson RM, Lambertsen CJ, Gelfand R, Hiller WDB, Unger M. Pulmonary function in men after oxygen breathing at 3.0 ATA for $3.5 \mathrm{~h}$. J Appl Physiol 1991; 71: 878-885.

5. Clark JM, Lambertsen CJ. Pulmonary oxygen toxicity: a review. Pharm Rev 1971; 23: 37-133.

6. Clark JM., Lambertsen CJ. Rate of development of pulmonary oxygen toxicity in man during oxygen breathing at 2.0 ATA. J Appl Physiol 1971; 30: 739-752.

7. Clark JM. Oxygen toxicity. In: Bennett PB, Elliott DH (eds.) The physiology and medicine of diving. London : W.B. Saunders Company Ltd; 1993, p. 121-169.

8. Clark JM. Pulmonary limits of oxygen tolerance in man. Exp Lung Res 1988; 14: 897-910.

9. Clark JM. The toxicity of oxygen. Am Rev Resp Dis 1974; 110: 40-50. 
10. Crapo JD. Morphologic changes in pulmonary oxygen toxicity. Ann Rev Physiol 1986; 48: 721-731.

11. Curley GF, Ansari B, Hayes M, Devaney J, Masterson C, Ryan A, et al. Effects of intratracheal mesenchymal stromal cell therapy during recovery and resolution after ventilator-induced lung injury. Anesthesiology 2013; 118 (4): 924-32 - doi: 10.1097/ ALN.0b013e318287ba08.

12. Demchenko IT, Welty-Wolf KE, Allen BW, Piantadosi CA. Similar but not the same: normobaric and hyperbaric pulmonary oxygen toxicity, the role of nitric oxide. Am J Physiol Lung Cell Mol Physiol 2007; 293: L229-L238.

13. Donald KW. Oxygen and the Diver. Harley Swan: The SPA Ltd; 1992.

14. Fisher AB, Bassett DJP, Forman HJ. Oxygen toxicity of the lung: Biochemical aspects. In: Fishman AP, Renkin E.M. (eds.) Pulmonary Edema. Bethesda: American Physiological Society; 1979. p. 207-216.

15. Freeman BA, Crapo JD. Biology of disease: Free radicals and tissue injury. Lab Invest 1982; 47: 412-426.

16. Gerschman R, Gilbert DL, Nye SW, Dwyer P, Fenn WO. Oxygen poisoning and x-irradiation: a mechanism is common. Science 1954; 119: 623-626.

17. Gerschman R. Biological effects of oxygen. In: Dickens F, Neil E. (eds.) Oxygen in the Animal Organism. New York: Macmillan; 1964. p. 475-494.

18. Hamilton RW. Tolerating exposure to high oxygen levels: Repex and other methods. Mar Tech Soc J 1989; 23: 19-25.

19. Harabin AL, Homer LD, Weathersby PK, Flyn ET. Predicting pulmonary O2 toxicity: a new look at the unit pulmonary toxicity dose. Report NMRI 86-52. Bethesda : Naval Medical Research Institute; 1986.

20. Jamieson D Oxygen toxicity and reactive oxygen metabolites in mammals. Free Rad Biol Med 1989; 7: 87-108.
21. Kapanci Y, Tosco R, Eggermann J, Gould VE. Oxygen pneumonitis in man: light and electron microscopic morphometric studies. Chest 1972; 62: 162-169.

22. Kapanci Y, Weibel ER, Kaplan HP, Robinson FR. Pathogenesis and reversibility of the pulmonary lesions of oxygen toxicity in monkeys. II. Ultrastructural and morphometric studies. Lab Invest 1969; 20(1): 101-118.

23. Kaplan HP, Robinson FR, Kapanci Y, Weibel ER. Pathogenesis and reversibility of the pulmonary lesions of oxygen toxicity in monkeys. I. Clinical and light microscopic studies. Lab Invest 1969; 20(1): 94-100.

24. Kistler GS, Caldwell PRB, Weibel ER. Development of fine structural damage to alveolar and capillary lining cells in oxygen-poisoned rat lungs. J Cell Biol 1967; 33: 605-628.

25. Konarski M, Kłos R, Siermontowski P. Preliminary evaluation of oxygen pulmonary toxicity risk during the oxygen tolerance test W: Olszański R., (red.) Wybrane problemy medycyny morskiej i nurkowej. Gdynia : Wyd. PTMiTH; 2012. p. 136-179 (in polish).

26. Lambertsen CJ Effects of hyperoxia on organs and their tissues. W: C Lenfant (Ed.) Lung biology in health and disease. Vol. 8: ED Robin (Ed.) Extrapulmonary manifestations of respiratory disease. New York : Marcel Dekker; 1978. p. 239-303.

27. Siermontowski P, Kozłowski W, Olszański R. Pedrycz A. The significance of an experimental model of pulmonary barotraumas in examining diving accidents. Pol Hyp Res 2012; 1: 7-28.

\section{Correspondence address:}

Ass. Prof. Piotr Siermontowski MD PhD Department of Maritime \& Hyperbaric, Medicine Military Institute of Medicine, 81-103 Gdynia, Poland 